\title{
Hegel y el neo-hegelianismo francés: una nueva identidad
}

\author{
Hegel and French neo-Hegelianism: \\ A new identity \\ MARÍA JOSÉ BINETTI \\ Conicet, Argentina
}

Recibido: 06-02-2007 Aprobado definitivamente: 13-06-2007

RESUMEN

Lejos de romper con el idealismo absoluto de Hegel, la filosofía francesa contemporánea parece asegurar su continuación. En efecto, el nuevo concepto de identidad mediante el cual la especulación hegeliana superó la rigidez inmóvil de la sustancia y la lógica bipolar del pensamiento representativo, ha sentado las bases especulativas de lo que el pensamiento francés reinscribe hoy bajo las categorías de diferencia, repetición, diseminación, imposibilidad, exceso, paradoja, instante, etc. El eterno retorno de lo mismo, el acontecimiento que sobreviene a la finitud y la aporía de una contradicción realizada son otros tantos nombres con los cuales la «escuela de la diferencia» reclama la racionalidad de una Aufhebung, que desborda y contiene toda discriminación abstracta.

PALABRAS CLAVES

IDENTIDAD, DIFERENCIA, OPOSICIÓN, MEDIACIÓN

\begin{abstract}
Far from breaking with Hegel's Absolute Idealism, French Contemporary Philosophy seems to ensure its continuity. In fact, the new concept of identity through which the Hegelian speculation overcame the immovable rigidity of substance and the bipolar logic of representative thought, has settled the speculative base of what nowadays French Philosophy includes again under the categories of difference, repetition, dissemination, impossibility, excess, paradox, instant, etc. The eternal return of the same, the event that happens to finite and the aporia of an actual con-
\end{abstract}

CC Contrastes. Revista Internacional de Filosofía, vol. XIII (2008), pp. 295-311. ISSN: 1136-4076

Licenciatura de Filosofía, Universidad de Málaga, Facultad de Filosofía y Letras

Campus de Teatinos, E-29071 Málaga (España) 
tradiction are different names through which the «school of difference» claims the rationality of Aufhebung, which overflows and contains all abstract discrimination.

KEY WORDS

IDENTITY, DIFFERENCE, OPPOSITION, MEDIATION

\section{INTRODUCCIÓN}

LEJOS DE ENTENDER LA FILOSOFÍA CONTINENTAL CONTEMPORÁNEA COMO Una ruptura con el idealismo absoluto de G.W.F. Hegel, consideramos que el pensamiento actual debe gran parte de su vigor especulativo a la profundización y continuación de la filosofía hegeliana. Nos referimos en particular a los autores franceses que componen lo que podría denominarse la «escuela de la diferencia», enriquecida con las múltiples perspectivas estéticas, sociológicas, psicoanalíticas, lingüísticas, gramaticales, históricas y filosóficas de G. Bataille, J. Lacan, J. Derrida, G. Deleuze, M. Blanchot, J.-L. Nancy, M. Foucault y F. Lyotard, entre otros.

La confluencia especulativa de estos autores responde esencialmente al desarrollo de una misma intuición fundamental, incardinada en el legado especulativo de Hegel. Lo que intentamos decir es que el concepto de «diferencia», propuesto por el pensamiento francés contemporáneo como dinamismo esencial de lo real, parece ser el nuevo nombre de una «identidad», con la cual Hegel ha roto la rigidez inmóvil de la sustancia y la lógica binaria del pensamiento representativo. En este sentido, la especulación hegeliana determinaría el punto de ruptura e inflexión, a partir del cual se ha edificado lo que nuestro tiempo concibe bajo las categorías de diferencia, repetición, diseminación, imposibilidad, exceso, paradoja, instante, etc.

El objetivo de las siguientes páginas consiste en iluminar esta convergencia esencial, de cuya vitalidad dependen el presente y el futuro del pensamiento. Nos detendremos brevemente sobre el pensamiento hegeliano y luego sobre la filosofía francesa, a fin de detectar el acuerdo intrínseco que los une.

\section{G. W. F. HEGEL: PUNTO DE RUPTURA E INFLEXIÓN}

Tanto por oposición al dualismo kantiano, escindido entre la inconsistencia fenoménica y el abandono de la infinitud en sí, como por oposición a la identidad formal de Schelling, cuya intuición de lo absoluto peca de ingenuidad irreflexiva, la filosofía de Hegel se decide por una totalidad inmanente, que explique el contenido propio de la experiencia sin perderse en dicotomías insalvables ni en vacías abstracciones. El pensamiento hegeliano ofrece de este modo -en su doble reclamo al iluminismo y al romanticismo- la primera y definitiva crítica 
de la modernidad, ${ }^{1}$ capaz de superar el paradigma de la conciencia representativa y del sujeto inmediato.

El idealismo post-crítico de Hegel propone reemplazar el modelo dualista sujeto-objeto, deseo-deber, ser-pensamiento, infinitud-finitud, por una efectividad conceptual -reflexiva y diferencial-cuya totalidad se expresa en la actividad especulativa como dinamismo deconstructor de la intuición inmediata y del entendimiento abstracto. La filosofía debe elevarse al esfuerzo del concepto, y esto significa que ella debe aprehender de manera ontológica el devenir inmanente y dialéctico, temporal y contingente de la idea. La especulación consiste entonces en la compresión absoluta de la existencia y de la historia, tan necesaria como provisional.

La Ciencia de la lógica responde a la exigencia del concepto con el esfuerzo de reflejar las categorías constitutivas de la realidad, a lo largo del proceso que la conduce hacia sí misma. La lógica es la ciencia de un absoluto que se produce en su propia diferenciación como creación de sentido, de logos, de inteligibilidad real. Y puesto que lo absoluto es el movimiento generador de sí a través de su propia diferencia, su ciencia traduce tal dinamismo en una multiplicación de sentidos, implicados y superados, presupuestos y sobrepuestos a cada momento de su desarrollo. Tal sucede con la categoría del ser, comienzo inmediato de la Lógica y sin embargo infinitamente presupuesto y mediado por su propio devenir esencial.

El ser representa la inmediatez de un despliegue diferencial, él mismo mediado y resultado del devenir que afirma y resuelve su identidad y su noidentidad, su diferencia y su igualdad con la nada. ${ }^{2}$ El devenir manifiesta la imposibilidad de un ser abstracto y excluyente del otro, por la realización de su pertenencia intrínseca a la nada. Él afirma y resuelve la oposición, y de aquí que signifique para Hegel la unidad conceptualizante del ser, por la cual éste queda comprendido en su negatividad. Sin embargo la negatividad del ser, afirmada y superada en la motilidad que lo constituye, traspasa a una negación más profunda: la alteridad reflexiva de su esencia, entendida por Hegel como la inmediata negatividad del ser. ${ }^{3}$

La comprensión de la esencia como pura negatividad autodeterminante del ser implica una ruptura fundamental con su clásica concepción en los términos de una infinitud positiva, simple y trascendente. En efecto, la esencia

$1 \quad C f$. Robert B. Pippin, Modernism as a Philosophical Problem, Blackwell, Oxford 1991, p. 164.

$2 C f$. G. W. F. Hegel, Ciencia de la lógica, tr. R. Mondolfo, Solar - Hachette, Buenos Aires 1968, pp. 77 ss; también Enciclopedia de las ciencias filosóficas en compendio: para uso de sus clases, tr. R. Valls Plana, Alianza, Madrid 2005, §§ 84 ss.

$3 C f$. G. W. F. Hegel, Ciencia de la lógica..., cit., pp. 345 ss.; cf. también Enciclopedia..., cit., $\S § 112-114$. 
no representa para Hegel la inmovilidad de una perfección incausada sino el dinamismo relacional de un absoluto, que se niega en la inmanencia múltiple de lo existente. Sobre la translúcida simplicidad de lo inmediato, la negatividad esencial denuncia lo otro, el doblez inverso de lo mismo, el pliegue que esconde la sospecha reflexiva de toda apariencia.

La esencia constituye un pasado atemporal e infinito, de cuyo recuerdo el ser emerge en la existencia temporal y finita. Ella determina lo que el ser era - tó ti en einai- antes de alcanzar la presencia del tiempo, y lo que siempre será el advenir una vez acontecido. Dicho de otro modo, la esencia es la repetición infinita del ser, su eterno retorno, la memoria activa de la finitud, que convierte lo futuro en un reditus circular. Su virtualidad infinita supone que lo existente sea más y diferente de lo manifestado en cada momento, y de aquí que ella exceda lo finito, desborde sus límites y transgreda su entera determinación. No obstante, y por tratarse aquí de un dinamismo reflexivo, la contradicción producida en lo existente por el exceso de lo esencial, se realiza y se resuelve en lo que Hegel denomina «efectividad».4

Del mismo modo en que el devenir produce y resuelve la contradicción del ser, la efectividad produce y resuelve la paradoja de una esencia negada en su propia afirmación existencial. Lo efectivo pone y supera la diferencia esencial, al modo de una relación o mediación absoluta que reestablece la unidad de lo existente sin absorberlo. Si la esencia es para Hegel lo uno, el todo y lo idéntico, no lo es en el sentido de una abstracción inmóvil sino en el de una efectividad relacional, cuya enérgeia infinita despliega la dúnamis indetenible del tiempo y el espacio. Ella constituye la identidad de esta actualización dinámica, que repite al infinito la negación de su diferencia.

Precisamente aquí reside la enorme revolución del pensamiento hegeliano, que ha quebrado la historia precedente y ha iniciado un nuevo modo de pensar. La revolución producida por Hegel es especulativa, y esto significa que ella es práctica, existencial, concreta. Su exigencia conceptual, que ha desenmascarado e invertido la realidad entera, reclama simplemente «la identidad en la diferencia y la diferencia en la identidad». ${ }^{5}$

Hegel ha revolucionado el pensamiento filosófico con un nuevo concepto de identidad, capaz de superar el dualismo del entendimiento representativo y de dominar la lógica formal de las oposiciones binarias, absolutas e inamovibles. Para el entendimiento abstracto, todo ser representa una entidad estática, firme y positiva, relacionada de manera extrínseca con otras tantas entidades abstractas y disuelta finalmente en el proceso indefinido de una mala infinitud.

$4 \quad C f$. G. W. F. Hegel, Ciencia de la lógica..., cit., pp. 479 ss.; cf. también Enciclopedia..., cit., $\S \S 142$ ss.

$5 \quad$ G. W. F. Hegel, Enciclopedia..., cit., § 118. 
En el contexto de esta lógica, los principios de identidad y de no contradicción erigen la simplicidad inmóvil y la eterna presencia de lo uno como ley universal del pensamiento y del ser. Sin embargo, la identidad defendida por ellos resulta para Hegel una vacua tautología, fruto de la irreflexión e incapaz de concebir el dinamismo diferencial inmanente a lo idéntico. El reclamo de Hegel insiste en que la proposición $\mathrm{A}=\mathrm{A}$ se desmiente por su propia forma-vale decir, por la diferencia entre el sujeto y el predicado- además de ser desmentida por la contradicción efectiva de A como mediación esencial de su igualdad. Respecto de la pretendida identidad formal, la tarea de la especulación consiste en volver sobre el entendimiento finito, a fin de concebir la racionalidad de todo por la superación de su unilateralidad binaria y excluyente.

La identidad propuesta por Hegel se dice concreta, reflexiva y dinámica. Ella constituye la efectividad de su propio devenir, en los términos de una «relación negativa consigo misma o diferenciación de sí». ${ }^{6} \mathrm{Su}$ dinamismo produce simultáneamente la oposición y la unidad, lo otro y lo mismo o, mejor dicho, los produce intrínsecamente como momentos de su totalidad progresiva y sintética. La identidad es en su diferencia, en su negatividad, en la alteridad que la confronta consigo misma. Porque ella sólo existe como efectividad de lo otro, lo mismo abre con su duplicación el espacio de una relación infinita, en la cual emergen el mundo, el tiempo y el devenir.

El fundamento de lo real no reside en la simplicidad eterna e inmóvil del ser sino en su negatividad infinita. En el origen no es ni la pura presencia ni la pura ausencia sino su mutua separación, la apertura de lo otro y el extrañamiento del ser. Porque la esencia es reflexión y negación, el substrato de las cosas consiste en el rechazo de lo uno y la mediación de lo otro. El fundamento opera como des-fundamentación negativa de lo real, y de este modo lo expele todo a su propia alteridad. Hegel somete la verticalidad lineal de lo absoluto a la horizontalidad lineal de lo finito, y así reemplaza ambas líneas por el círculo de los círculos, imagen de una infinitud efectiva, inmanente y reduplicada en todo. El círculo representa metafóricamente la diferenciación infinita de la identidad, conforme con la cual cada punto, cada momento, cada individuo es principio y fin, comienzo y resultado, inmediata presuposición y posición mediada, centro y extremo de la totalidad.

Lo que Hegel denomina «mediación»-a menudo confundida con un tercer estado fijo y subsistente o con una yuxtaposición de opuestos- designa propiamente el pasaje, el devenir, la efectividad que afirma y resuelve las diferencias, el traspasar reflexivo que se abre a la alteridad. El ser y la nada, la esencia y la existencia, lo universal y lo individual son, en la mediación, la repetición diferencial del exceso que los presupone, los pone y los supera. Porque la mediación 
precede la inmediatez, cada momento asume lo absoluto, por un movimiento circular cuyo resultado se invierte a sí mismo.

Lo que el entendimiento finito fija, define y cierra, el concepto lo niega, invierte y abre. Lo que la lógica formal separa y excluye, la razón lo une e incorpora. La filosofía hegeliana es lo suficientemente dialéctica para mantener el interjuego continuo de los opuestos, en el cual ambos permanecen porque los dos han sido negados. Su identidad no significa un absolutismo abstracto sino una actualización temporal y finita de lo absoluto. Su totalidad no equivale a la clausura del mundo y de la historia sino a la repetición totalizante de cada momento. Lo idéntico consiste en el dinamismo temporal y en la manifestación múltiple de la existencia, y sólo porque lo mismo es lo otro, hay devenir y exterioridad, reflexión y traspaso. Dicho brevemente, la diferencia constituye la verdad de la identidad.

El eterno retorno de lo finito, su absoluta repetición y su continuo devenir confirman de manera palmaria el nuevo concepto de identidad aportado por Hegel, según el cual «todo lo que existe muestra en él mismo que en su igualdad consigo es desigual y contradictorio, y que a pesar de su diferencia y contradicción es idéntico consigo mismo». ${ }^{7}$ La existencia finita insiste en su desigualdad y contradicción, en la negatividad que la constituye y, a la postre, en su propia superación como autentificación ontológica. Su identidad le pertenece a ese «delirio báquico», ${ }^{8}$ cuya embriaguez transluce la armonía de lo absoluto. En este sentido, el gran arte de la especulación hegeliana consiste en la disolución de todo contenido fijo y en el despliegue de una relacionalidad dinámica que todo lo excede.

El carácter relacional, y por lo tanto diferencial, que constituye lo idéntico se manifiesta en diversos niveles de comprensión real. ${ }^{9}$ En un primer momento, ella indica la diversidad extrínseca e indeterminada de una multiplicidad de seres iguales o desiguales. En segundo lugar, la relación se establece como oposición binaria, excluyente de sus términos. En última instancia, la polaridad diferencial deviene una contradicción interna, que escinde y reduplica la mismidad. Lo existente implica de este modo una contradicción en sí, cuya superación no reside en el tercer estado de una identidad abstracta sino el dinamismo paradojal que la realiza. La contradicción de una plenitud desbordante, el exceso fundador y desfundador de lo finito: tal es la identidad concreta que Hegel propone.

7 G. W. F. Hegel, Ciencia de la lógica..., cit., p. 362.

$8 C f$. G. W. F. Hegel, Fenomenología del espíritu, tr. W. Roces, Fondo de Cultura Económica, México 1966, p. 32.

9 Cf. G. W. F. Hegel, Ciencia de la lógica..., cit., pp. 366-389; cf. también Enciclopedia..., cit., §§ 116-119. 
La afirmación según la cual «el no-ser de lo finito es el ser de lo absoluto» $»^{10}$ expresa tanto la diferencia como su superación. El no-ser de lo finito es -por la mediación- su verdadero ser, en el mismo sentido en el cual lo absoluto constituye -en la mediación- la concreción intensiva del devenir temporal. Lo absoluto consiste en la afirmación de la finitud y de este modo él converge, por el principio de la inversión, con la negación de lo finito como superación de sí mismo. El círculo total en el cual se abrazan la linealidad de lo finito y la verticalidad de lo absoluto es presupuesto y resultado de esta identidad dinámica, dialéctica y relacional, en la que ser y nada se traspasan mutuamente.

Porque en el origen no es la identidad abstracta sino el dinamismo de la escisión, el ser de lo absoluto es igualmente el no-ser de lo finito, y esto significa que Dios muere en el mundo a fin de que lo otro pueda existir. La muerte de lo divino contiene toda «la seriedad, el dolor, la paciencia y el trabajo de lo negativo» ${ }^{11}$ como único medio de su afirmación. Dios se atreve al mal y por eso es que -como lo subraya J. Hyppolite- el pantragismo de la historia y el panlogismo de la lógica son para Hegel una misma realidad. ${ }^{12}$ Porque lo absoluto tiene el coraje y la paciencia de lo negativo, lo finito está signado por la muerte, pero por una muerte y una negatividad absolutamente superadas. El panlogismo de Hegel es incapaz de detener la diferencia del todo, y aquí reside su tragedia: en una repetición incansable que reinscribe por doquier el exceso de lo divino. Lo absoluto constituye el no-ser que divide y multiplica todas las cosas, las desfonda e invierte. Sin embargo, precisamente porque para Hegel el centro está en todas partes, lo absoluto es también el medio y la unidad intrínseca de una relación infinita.

Desde el punto de vista ético, la deconstrucción especulativa de la lógica formal implica que ya «no hay lo falso como no hay lo malo», ${ }^{13}$ esto es, implica la superación de la bondad y la maldad, la verdad y la falsedad objetivamente acuñadas como monedas claras y distintas de un intercambio exacto y seguro. Lo que hay en el lugar de estas rígidas abstracciones consiste en un exceso de infinitud, incapaz de ser fijado y asegurado por el entendimiento finito. Más allá del bien y del mal, el fundamento ético se sobrepone a la separación, como fuerza efectiva a partir de la cual aquella se produce y se resuelve.

La tan celebrada y vapuleada «razón» indica para Hegel esta concreción omninclusiva, realizadora de una contradicción imposible para la representación

10 G. W. F. Hegel, Ciencia de la lógica..., cit., p. 389.

11 G. W. F. Hegel, Fenomenología..., cit., p. 16.

12 Cf. J. Hyppolite, Génesis y estructura de la "Fenomenología del Espíritu" de Hegel, tr. F. Fernández Buey, $3^{a}$ ed., Península, Barcelona 1998, p. 31; también J. Hyppolite, Logique et existence. Essai sur la logique de Hegel, Presses Universitaires de France, Paris 1953, $p$. 149 .

13 G. W. F. Hegel, Fenomenología..., cit., p. 27. 
intelectual. Lo que el entendimiento abstracto considera irracional, falso, paradójico, la razón lo supone en su propio dinamismo absoluto. En este sentido, J. Hyppolite ha subrayado que «Hegel es el más grande irracionalista y el más grande racionalista que haya existido», ${ }^{14}$ mientras que J. Wahl considera su especulación en los términos de un «romanticismo encubierto». ${ }^{15}$ Ciertamente, si por razón se entiende el otro nombre de lo mismo que los escritos juveniles de Hegel denominaban amor, ${ }^{16}$ no hay dudas de que se trata aquí de un romanticismo, fundado en la experiencia de la libertad y en la certeza ontológica de lo absoluto. El conocimiento propuesto por Hegel como desenlace del devenir espiritual -tantas veces confundido con la rigidez de las representaciones abstractas o con la clausura temporal de la historia- consiste en la experiencia liberadora de esta unidad amorosa, descubierta en todas partes y repetida a cada momento.

La enorme revolución especulativa producida por Hegel reside en asignar a la diferencia el derecho de la identidad. Su filosofía no elimina la alteridad de lo absoluto, ni la oposición de lo universal y lo singular, ni la discontinuidad entre Dios y el hombre. ${ }^{17}$ Todo lo contrario, ella le confía a lo otro la construcción de una unidad dinámica y dialéctica. El universo se juega en un báquico delirio, cuya translúcida quietud escribe el texto de la diferencia. De Hegel se sigue que somos, nos movemos y existimos en la diseminación total, precisamente por ser y por movernos en la posibilidad de lo absoluto. Tiempo, historia y finitud concretan un proceso intrabsoluto, donde la eternidad y lo infinito están siempre presentes sin ser nunca representados ni agotados. La propuesta hegeliana es la de una continua diferenciación de lo mismo, y de aquí que su pensamiento permanezca abierto, a la espera de una nueva determinación absoluta.

La ruptura de la identidad aportada por Hegel representa sin duda una significativa transformación en el modo de experimentar y concebir lo real, cuyos efectos apenas hemos comenzado a transitar.

14 J. Hyppolite, Logique et existence..., cit., p.131.

15 J. Wahl, La lógica de Hegel como fenomenología, tr. A. Llanos, La Pleyade, Buenos Aires 1973, p. 129.

$16 C f$. J. Hyppolite, Logique et existence..., cit., p. 24.

$17 C f$. R. Valls Plana, Del yo al nosotros. Lectura de la Fenomenología del espíritu de Hegel, $1^{\text {a }}$ ed., Estela, Barcelona 1971, p. 315. 


\section{EL «NEO-HEGELIANISMO» FRANCÉS}

El impacto de Hegel sobre la filosofía francesa contemporánea se debe en gran medida a las lecciones dictadas por A. Kojève ${ }^{18}$ y J. Hyppolite ${ }^{19}$ sobre la Fenomenología del espíritu. Ambos intérpretes coicidieron en subrayar la noción de «diferencia» como clave de la especulación hegeliana y, en torno de esta noción, cobraron relevancia las categorías de contingencia, temporalidad, alteridad, paradoja, exceso, repetición, que dominan el pensamiento de G. Bataille, J. Derrida, G. Deleuze, M. Blanchot, J.-L. Nancy, M. Foucault y F. Lyotard, entre otros.

Más allá del nexo historiográfico establecido por Kojève y Hyppolite, nexo que supone además, en menor o mayor medida según los casos, la recepción de K. Marx, S. Kierkegaard, F. Nietzsche o M. Heidegger, lo que nos interesa destacar en estas líneas consiste en la convergencia especulativa entre el pensamiento de Hegel y las categorías comunes y determinantes de la filosofía francesa contemporánea. Ante todo, debemos aclarar que la clave de la comparación no se encuentra en el concepto de diferencia -oposición o negatividad-sino más bien en la noción de identidad y, particularmente, en la nueva concepción de lo uno aportada por Hegel. En efecto, se trata aquí de una identidad cuya realización le pertenece a lo otro. A este tipo de identidad dinámica y esencialmente relacional se la llama hoy «diferencia».

En un intento por asir la continuidad histórica dentro de la cual se hace posible pensar, J. Derrida ha asegurado que «nunca terminamos de leer o releer a Hegel y, en cierto sentido, yo no hice más que intentar explicarme a mí mismo sobre este punto». ${ }^{20}$ Derrida considera a Hegel como «el primer pensador de la escritura» ${ }^{21}$ y esto significa -en los términos de la especulación derridiana- el primero en quebrar el origen inmaculado y el fin trascendente de lo real, a fin de sustituir el sistema cerrado del libro por la inmanencia diferencial y la infinita repetición de la escritura. En este sentido, bajo el nombre de différance, Derrida se explica sobre Hegel.

$18 C f$. A. Kojève, Introduction à la lecture de Hegel: leçons sur la «Phénomenologie de l'esprit» professées de 1933 à 1939 à l'École des Hautes-Études, ed. Raymond Queneau, Paris, Gallimard 1947. Al seminario de Kojève asistieron, entre otros, R. Aron, G. Bataille, A. Koyré, P. Klossowski, J. Lacan, M. Merleau-Ponty, E. Weil, G. Fessard y A. Breton.

19 Cf. J. Hyppolite, Génesis y estructura..., cit.; también Logique et existence..., cit. La traducción de Hyppolite a la Fenomenología del espíritu de Hegel fue publicada por partes a partir de 1939. Su Tesis doctoral, Génesis y estructura de la Fenomenología, fue publicada en 1946. Entre los alumnos de Hyppolite se incluyen F. Foucault, G. Deleuze, L. Althusser and J. Derrida.

20 J. Derrida, Positions, Les Éditions de Minuit, Paris 1972, pp. 103-104.

21 J. Derrida, De la Grammatologie, Les Éditions de Minuit, Paris 1967, p. 41. 
La derridiana différance no pretende ser ni diferencia ni identidad, ni presencia ni ausencia, ni ser ni pensamiento finito, ni interioridad ni exterioridad, ni afirmación ni negación. ${ }^{22}$ Todo lo contrario, ella propone superar las discriminaciones finitas de la conciencia inmediata y del pensamiento representativo, para ubicarse en el lugar de una identidad dinámica, llamada a diferenciarse infinitamente en la escritura de lo real. La lógica binaria del entendimiento abstracto -que para Hegel ha justificado la alienación, política y religiosa del hombre-justifica para el pensamiento francés contemporáneo la exclusión social, la discriminación y el totalitarismo. De aquí la importancia de su superación, como fundamento especulativo de la igualdad y la justicia. Desde el punto de vista del entendimiento abstracto, la nueva lógica de la différance representa una aporía, entendida por Deleuze como la paradoja de una identidad infinita ${ }^{23}$ y por Foucault como la locura que acompaña toda inteligencia. ${ }^{24}$ No obstante, solo la loca aporía de este logos omninclusivo puede salvar la racionalidad concreta de las cosas.

Mas allá de las oposiciones finitas, la différance se afirma como un «tercer genero» ${ }^{25}$ de realidad -el género neutro de Blanchot ${ }^{26}-$, cuya plenitud indeterminada excede toda discriminación y cuya intensidad inagotable presupone virtualmente toda oposición y diferencia. Lo finito contiene de este modo un plus de infinitud, una exhuberancia desbordante, un exceso desmesurado, en el cual él se presupone, se sostiene y se supera. Lyotard lo denomina el «enigma del exceso», ${ }^{27}$ precisamente porque su presencia absoluta es impresentable al intelecto abstracto y sin embargo manifiesta al sentimiento de lo sublime. ${ }^{28}$ Derrida, por su parte, lo llama la «experiencia de lo imposible», ${ }^{29}$ capaz de fundar toda posibilidad.

El exceso enigmático e imposible de la différance constituye el fundamento y el origen de todo, pero no al modo de una perfección inmóvil y ejemplar sino al modo de un infinito desgarramiento, que afirma lo absoluto en la escisión de sí mismo. El origen no es entonces una causa incausada, porque él se produce en la posición de lo otro. Él no es tampoco un modelo trascendente, porque su esencia existe en la inmanencia de la finitud. No se trata de un fundamento puro y simple, dado que contiene su separación, y menos que nada de un acto inmóvil

22 Cf. J. Derrida, Marges de la Philosophie, Les Éditions de Minuit, Paris 1972, pp. 6 ss.

$23 C f$. G. Deleuze, Logique du Sens, Les Éditions de Minuit, Paris 1969, p. 10.

$24 C f$. M. Foucault, Folie et déraison. Histoire de la folie. A l'age classique, Union Générale d'Éditions, Paris 1961, p. 304.

25 J. Derrida, Khôra, Galilée, Paris 1993, p. 16.

26 Cf. M. Blanchot, Le Pas Au-Delà, Gallimard, Paris 1973, p. 108.

27 J.-F. Lyotard, Moralités postmodernes, Galilée, Paris 1993, p. 29.

28 Cf. J.-F. Lyotard, Leçons sur l'analytique du sublime, Galilée, Paris 1991.

29 J. Derrida, Force de loi, Galilée, Paris 1994, p. 35. 
y sustancial, puesto que es pura virtualidad dinámica. Ante tales razones, el pensamiento contemporáneo ha declarado la inaccesibilidad e imposibilidad del origen, ${ }^{30}$ y esto significa que la esencia se afirma en su propia negación y sostiene lo finito en la des-fundamentación de sí misma. Si -como quiere Deleuze ${ }^{31}$ - la idea presupone la autodiferenciación múltiple de lo otro, entonces ella repite al infinito el acontecimiento de su mismidad fundadora.

La trascendencia inmóvil de la causa primera ha sido reemplazada por la inmanencia dinámica de un absoluto, que se adviene y sobreviene al acontecimiento de lo real. La identidad constituye de este modo el à venir de sí misma y su acontecer abre el espacio de la existencia finita como reduplicación temporal y contingente de lo eternamente sido. La apertura y el despliegue del événement ${ }^{32}$ manifiesta la virtualidad infinita de lo esencial, concretada en el devenir efectivo del mundo. En este sentido, la finitud se supera a sí misma en el acontecimiento de su propia donación, en la misma medida en la cual ella produce lo donado, por una diferenciación inagotable que realiza y conserva lo esencial.

En el origen no es ni la infinitud ni la finitud abstracta, sino la superación de ambas en tanto que dinamismo reflexivo y diferencial, duplicador y relacional. Ni la eternidad ni el tiempo fundan lo real sino en el devenir, como pasaje permanente que «no sucede a una diferencia sino que precede y hace posible la diferencia», ${ }^{33}$ precisamente por superarla. Dicho de otro modo, en el origen es la mediación, por la cual «el Otro, el Lejano, es también el más Cercano y el Mismo». ${ }^{34} \mathrm{El}$ fundamento repite una mismidad siempre sida que continuamente empieza a ser. Y esto es lo que Derrida denomina -con una expresión tomada de Hegel- la «relación diferenciante», ${ }^{35}$ constitutiva de toda presencia por la escisión de sí misma.

En tanto que «diferenciante», la relación produce lo finito por la violencia irreductible de la inversión, del detour ${ }^{36}$ de la diseminación y el flujo. Ella imprime a lo real la forma de una conexión múltiple, establecida en el desdoblamiento esencial de todas las cosas. Nada es simple, todo se duplica, y solo el «pliegue» ${ }^{37}$ de su reflexión transluce la armonía del báquico delirio. La diferencia temporaliza, espacializa y mantiene abierto el juego de la existencia. Ser, pensamiento y

$30 C f$. M. Foucault, Les mots et les choses. Une archéologie des sciences humaines, Éditions Gallimard, Paris 1966, p. 343; M. Blanchot, L'Entretien infini, Gallimard, Paris 1969, p. 64 .

31 Cf. G. Deleuze, Différence et répétition, Puf, Paris 1968, p. 358.

32 Cf. G. Deleuze, Logique..., cit., pp. 206-207; J. Derrida, Force..., cit., pp. 60-61.

33 J.L. Nancy, La remarque spéculative. Un bon mot de Hegel, Galilée, Paris 1973, p. 53.

34 M. Foucault, Les mots..., cit., p. 350.

35 Cf. J. Derrida, Marges..., cit., pp. 14-15.

36 M. Blanchot, L'Entretien..., cit., p. 254.

37 Cf. G. Deleuze, Le Pli, Minuit, Paris 1988 
poder pierden de este modo su sustancialidad monolítica, para asumir la proteica figura de una multiplicidad cambiante y reversible. La duplicación conceptual que diferencia lo idéntico supone de este modo la posibilidad inagotable de lo finito por el exceso mismo de su infinitud imposible.

Pero además, y en tanto que relacional, la diferencia establece el milieu $^{38}$ de lo opuesto, el entre-dos de la dialéctica, el elemento de lo mismo y el centro omnipresente que domina toda rizomática formación. Con la perfección de un dinamismo circular, la relación reproduce el medio en todas partes y la indecidibilidad en cada determinación. Sin su mediación, el perpetuum mobile de la existencia, cuya paradoja reduce los contrarios a su intrínseca identidad, se convertiría en una abstracción inmóvil. Y tal sucedería también si la mediación significara un tercer estado estático, en lugar de un original dinamismo superador, indeconstruible y excesivo, incalculable e imposible.

La efectividad mediadora de la diferencia constituye lo que -bajo la inspiración del pensamiento kierkegaardiano- lleva el nombre de «repetición». Por repetición se entiende el devenir estructurante de lo real, mediante el cual la alteridad es producida y contenida en un mismo acto absoluto. Para que esto ocurra son tan necesarias la diferencia como la identidad, sin que la repetición sea ninguna de ellas sino la «esencia ternaria $»^{39}$ que las reúne intrínsecamente. La naturaleza ternaria de lo repetido contiene su escisión diferencial en la paradójica unidad de un movimiento que permanece -según Deleuze- en la interioridad de la idea como creación de su propia alteridad. ${ }^{40}$ Lo repetido es la eternidad de lo finito en la finitud de lo eterno, el retornar mismo de lo múltiple como identidad de su contenido esencial.

El eterno retorno de la idea, cuyo exceso infinito se convierte en realidad, vuelve incansablemente al tiempo, al espacio y a la finitud, para repetir el mundo a cada instante. La categoría del «eterno retorno» sólo es especulativamente concebible a partir de lo negativo como diferir intrínseco de la identidad. Si la eternidad es capaz de retornar, lo que siempre vuelve es su diferencia temporal, contingente, mortal. De aquí que el eterno retorno constituya la síntesis de una doble afirmación, a saber, la afirmación universal del ser uno y mismo, mediada por la afirmación singular del devenir múltiple y otro. Se trata aquí de un silogismo perfecto: círculo de los círculos y «movimiento de recurrencia del cual Hegel proveyó el modelo». ${ }^{41}$ Precisamente porque todo retorna, el advenir retrocede y «el origen es entonces lo que está por volver». ${ }^{42}$ En la circularidad

38 Cf. J. Derrida, Khôra..., cit., p. 46; G. Deleuze, Logique..., cit., p. 98; J. Derrida, Positions..., cit., p. 17.

39 J. Derrida, L'écriture et la différence, Éditions du Seuil, Paris 1967, p. 435.

40 Cf. G. Deleuze, Différence..., cit., p. 36.

41 M. Blanchot, Le Pas..., cit., p. 54.

42 M. Foucault, Les mots..., cit., p. 343; también M. Blanchot, Le Pas..., cit., p. 21. 
perfecta de esta Aufhebung, el retorno del origen coincide con la expectación de lo futuro, y lo que siempre ha sido resulta lo todavía por venir.

A esta superación mediadora del tiempo y la eternidad, el pasado y lo futuro, el pensamiento francés contemporáneo la denomina «instante» o «aiôn». ${ }^{43} \mathrm{El}$ instante constituye el centro y el extremo, el todo y la parte, que convierte a cada tiempo en el tiempo entero de lo eterno. Él reproduce en lo temporal el mismo dinamismo identificador que el devenir produce en la diferencia esencial del ser. En lugar del presente cronológico, representado por el entendimiento finito como la fracción estática de un fluir indetenible, el aiôn expresa la paradójica duplicación conceptual de una presencia, devenida el pasado inmemorial de un futuro siempre abierto.

Ahora bien, la misma duplicación conceptual que hace posible la mediación instantánea del tiempo y la finitud, hace necesaria la muerte de lo divino en tanto que abstracta representación de una infinitud positiva y trascendente. Si el ser de lo absoluto es el no ser de lo finito, la muerte cumple el destino de lo divino. Dios muere en el mundo para repetir su vida al infinito. Él se inscribe en lo real $^{44}$ a fin de que el universo pueda acontecer. Nuevamente aquí, el pensamiento celebra la paradoja de un Dios diferido en el hombre y de un hombre elevado a lo divino. No hay yuxtaposición, no hay mezcla, no hay confusión. Hay la loca aporía de un in-sistir, que media la diferencia en la cual se afirma.

A la muerte de Dios se suma hoy la muerte del hombre, propuesta por el pensamiento contemporáneo como deconstrucción del sujeto claro y distinto, paradigma de la modernidad. Ciertamente, este modo de ser sujeto -si alguna vez ha existido- murió hace rato. De lo que se trata ahora es de superar las antinomias del entendimiento representativo y abstracto, a fin de conceptuar la duplicidad esencial del ser, su proliferación relacional, su exceso multiplicador, la repetición ideal de su diferencia. La emergencia del simulacro en reemplazo de la copia, del rizoma en lugar de la sustancia inmóvil y trascendente, no niega la idea sino que afirma su pertenencia a «un devenir-loco, un devenir ilimitado, un devenir siempre otro, un devenir subversivo de las profundidades». ${ }^{45}$ El báquico delirio de la identidad reinscribe de este modo la potencia de lo negativo por la cual aquella se afirma.

Desde el punto de vista práctico, la ruptura de la identidad -que ha matado a Dios junto con el hombre- se traduce en una nueva ética, determinada por la superación del dualismo objetivo entre lo bueno y lo malo, el sujeto y el objeto, la trascendencia y la inmanencia, el cielo y el infierno. Los caminos que nos han

43 Cf. G. Deleuze, Logique..., cit., pp. 192-193; M. Blanchot, Le Pas..., cit., pp. 21 ss.; J. Derrida, Donner Le temps. 1. La fausse monnaie, Galilée, Paris 1991, p. 21.

$44 C f$. J. Derrida, L'écriture..., cit., p. 170.

45 G. Deleuze, Logique..., cit., p. 298. 
traído hasta esta nueva ética son, en primer lugar, el dinamismo autofundacional del sujeto, presupuesto en el acto de su propia existencia como ley de sí mismo y fuente creadora de todo valor. En segundo lugar, nos ha traído hasta aquí la negatividad esencial de una libertad afirmada por su propia superación. En último lugar, hemos llegado a ella por el exceso de una infinitud concretada en lo finito, al modo de un bonum disseminativum de la pluralidad y el devenir.

La ética contemporánea asume la paradoja absoluta e indeterminada de lo uno como condición de posibilidad e imposibilidad para todo sentido y determinación finita. A este exceso indiferenciado responde lo que Derrida llama «la aporía de una responsabilidad ${ }^{46}$ y Deleuze denomina -volviendo a una expresión kierkegaardiana- «la suspensión teleológica de la ética». ${ }^{47}$ En ambos casos, se trata del esfuerzo por conceptuar una identidad indecidible e inefable, a partir de la cual lo ético se afirma como síntesis dinámica y relacional de la existencia humana, concretada en un instante abarcador de toda diferencia. Mientras que la ética clásica se ampara en el binomio lógico que excluye el bien y el mal conforme con el cálculo del entendimiento finito, la nueva ética se sostiene en un logos eterno que incluye su propia diferenciación conforme con la racionalidad concreta de lo real. Cuando la ética clásica impone el universo el tribunal trascendente del supremo bien, la ética contemporánea declara la absolución del devenir, eternamente justificado en sí mismo.

La nueva ética se instala más allá del bien y del mal, con la certeza de una culpa infinita indiscernible de su absoluta inocencia. Ser absolutamente culpable e infinitamente inocente son las dos caras de una misma identidad, en todo caso negada y siempre redimida. Por eso «día y noche, a cada instante, en todos los Montes Moriah del mundo, yo estoy haciendo esto, levantando mi cuchillo sobre lo que amo y debo amar, sobre quienes les debo absoluta fidelidad, inconmensurablemente». ${ }^{48}$ Haga lo que haga, toda acción paga con la culpa el precio de una inconmensurabilidad que la niega. Sin embargo también, haga lo que haga, la imposibilidad del exceso justifica de antemano la caída. En el mismo instante que la niega, la plenitud desbordante de lo finito libera la pureza del devenir.

Más allá del dualismo objetivo entre lo bueno y lo malo, lo verdadero y lo falso, la superación de su diferencia intenta romper con los sistemas de control y de manipulación, a fin de abrir el juego libre de la igualdad, el derecho al flujo, la justicia de lo otro. Desde la deconstrucción derridiana hasta la arqueología de Foucault, pasando por esquizo-análisis de Deleuze y Guattari, el pensamiento contemporáneo se ha esforzado en asir la racionalidad concreta de lo real, capaz

46 J. Derrida, Donner la mort, Paris, Galilée, 1999, p. 43.

47 G. Deleuze, Différence..., cit., p. 14.

48 J. Derrida, Donner..., cit., p. 98. 
de desenmascarar la lógica binaria de un poder, que ha reprimido la voz de la locura, del crimen, del delito, de la sexualidad, de la mujer, de lo inconciente. ${ }^{49}$ Precisamente porque lo racional es lo real, hoy es posible reconciliar lo que siempre ha estado allí y lo que eternamente se repetirá.

La ética contemporánea quiere ser «una ética de la Gelassenheit, es decir, una ética del dejar ser, del dejar en paz a los dioses y a los mortales, al cielo y a la tierra y permitirles continuar el juego». ${ }^{50} \mathrm{Si}$ la ética puede hoy dejar ser en paz la diferencia, es porque la especulación afirmó algún tiempo atrás su verdadera identidad. A este reconocimiento concreto de lo otro, la humanidad siempre ha llamado «amor».

\section{CONCLUSIONES}

Cuando Hegel asegura que «la fuerza del espíritu consiste en permanecer igual a sí mismo en su enajenación», ${ }^{51}$ afirma con ello la conceptualización dinámica de la identidad y la diferencia, que estructura toda experiencia y se verifica en cada momento y orden de lo real. Que la identidad sea la diferencia y que la diferencia constituya la identidad expresa el verdadero dinamismo de las cosas, en el cual la contradicción se presupone resuelta y la posición de la alteridad, superada. Una vez mediada la sustancia abstracta de lo uno, lo que queda es la producción de lo idéntico por el despliegue infinito de lo otro.

La ruptura de la identidad operada por Hegel ha sentado las bases especulativas de lo que el pensamiento francés contemporáneo no ha hecho más que reinscribir en diversas áreas y niveles de análisis. El eterno retorno de lo mismo, su infinita repetición, el exceso imposible del Otro, el acontecimiento que sobreviene a la finitud, el elogio de la locura y la paradoja de todos los sentidos a la vez son otros tantos nombres con los cuales la filosofía actual asume la racionalidad de una Aufhebung, que desborda y contiene toda discriminación abstracta. La perpetuidad del devenir y la apertura del aiôn confirman la mediación de un silogismo, cuya circularidad lo renueva todo. De Hegel se sigue que la falsedad, el mal, la muerte, lo negativo pertenecen por esencia a dios y al hombre, aunque también, por esencia, se justifican. Porque lo absoluto ha descendido a la tierra, el anillo de la eternidad garantiza la pureza del devenir.

En otros términos, podría decirse que una misma vena romántica recorre la especulación moderna y postmoderna. $\mathrm{Si}$-como afirma Blanchot- por ro-

49 Cf. M. Foucault, Folie...., cit.

50 J. Caputo, Radical Hermeneutics. Repetition, Deconstruction and the Hermeneutic Project, Indiana University Press, Bloomington 1987, p. 264.

51 G. W. F. Hegel, Fenomenología..., cit., p. 471. 
manticismo se entiende un exceso de pensamiento, que supera la totalidad del entendimiento abstracto a fin de mantener abierta la alternancia creadora de la libertad, ${ }^{52}$ no caben dudas de que no sólo la razón hegeliana sino también la paradoja de lo indecidible y la ausencia de la locura son un romanticismo encubierto.

El pensamiento de Hegel ha sido lo suficientemente dialéctico para no ceder ni ante la abstracción de una perfección trascendente ni ante la alienación de una conciencia irreconciliable. Frente a la lógica binaria del entendimiento representativo, él le impuso al pensar la duplicidad de una esencia capaz de perder su ingenuidad irreflexiva y al interjuego siempre móvil de lo alterno, la triplicidad de un concepto capaz de mantenerse en su igualdad.

Ante la inminencia del futuro, el desafío del devenir residirá en la destreza dialéctica, con la cual el pensamiento sea capaz de mantener la reduplicación de la diferencia en la triplicidad siempre nueva de la identidad.

\section{REFERENCIAS BIBLIOGRÁFICAS}

BLANCHOT, M., Le Pas Au-Delà, Gallimard, Paris, 1973.

BLANCHOT, M., L'Entretien infini, Gallimard, Paris, 1969.

CAPUTO, J., Radical Hermeneutics. Repetition, Deconstruction and the Hermeneutic Project, Indiana University Press, Bloomington, 1987.

DELEUZE, G., Logique du Sens, Les Éditions de Minuit, Paris, 1969.

DELEUZE, G., Différence et répétition, Puf, Paris, 1968.

DELEUZE, G., Le Pli, Minuit, Paris, 1988.

DERRIDA, J., De la Grammatologie, Les Éditions de Minuit, Paris, 1967

DERRIDA, J., L'écriture et la différence, Éditions du Seuil, Paris, 1967.

DERRIDA, J., Positions, Les Éditions de Minuit, Paris 1972.

DERRIDA, J., Marges de la Philosophie, Les Éditions de Minuit, Paris, 1972, pp. 6 SS.

DERRIDA, J., Apories, Galilée, Paris, 1996.

DERRIDA, J., Khôra, Galilée, Paris, 1993.

DERRIDA, J., Force de loi, Galilée, Paris, 1994.

DERRIDA, J., Donner la mort, Paris, Galilée, 1999.

DERRIDA, J., Donner Le temps. 1. La fausse monnaie, Galilée, Paris, 1991.

DESCOMBES, V., Lo mismo y lo otro. Cuarenta y cinco años de filosofía francesa (1933-1978), trad. Elena Benarroch, Cátedra, Madrid, 1979.

FOUCAULT, F., Folie et déraison. Histoire de la folie. A l'age classique, Union Générale d'Éditions, Paris, 1961.

FOUCAULT, M., Les mots et les choses. Une archéologie des sciences humaines, Éditions Gallimard, Paris, 1966. 
FOUCAULT, M., Histoire de la sexualité. 1. La volonté de savoir, Éditions Gallimard, Paris, 1976.

HEGEL, G. W. F., Ciencia de la lógica, trad. R. Mondolfo, Solar - Hachette, Buenos Aires, 1968.

HEGEL, G. W. F., Enciclopedia de las ciencias filosóficas en compendio: para uso de sus clases, trad. R. Valls Plana, Alianza, Madrid, 2005.

HEGEL, G. W. F., Fenomenología del espíritu, trad. W. Roces, Fondo de Cultura Económica, México, 1966.

KOJEVE, A., Introduction à la lecture de Hegel: leçons sur la «Phénomenologie de l'esprit» professées de 1933 à 1939 à l'École des Hautes-Études, ed. Raymond Queneau, Paris, Gallimard, 1947.

HYPPOLITE, J., Génesis y estructura de la "Fenomenología del espíritu" de Hegel, trad. F. Fernández Buey, $3^{a}$ ed., Península, Barcelona, 1998.

HYPPOLITE, J., Logique et existence. Essai sur la logique de Hegel, Presses Universitaires de France, Paris, 1953.

LYOTARD, J.-F., Leçons sur l'analytique du sublime, Galilée, Paris, 1991.

LYOTARD, J.-F., Moralités postmodernes, Galilée, Paris, 1993.

NANCY, J.-L., La remarque spéculative. Un bon mot de Hegel, Galilée, Paris, 1973.

PIPPIN, R. B., Modernism as a Philosophical Problem, Blackwell, Oxford 1991.

VALLS PLANA, R., Del yo al nosotros. Lectura de la Fenomenología del Espíritu de Hegel, $1^{\mathrm{a}}$ ed., Estela, Barcelona 1971.

WAHL, J., La lógica de Hegel como fenomenología, trad. A. Llanos, La Pleyade, Buenos Aires, 1973.

MARía José BinetTi es doctora en Filosofía por la Universidad de Navarra (España), actual becaria post-doctoral de Conicet (Argentina) y de la Hong Kierkegaard Library (USA).

Publicaciones recientes:

El poder de la libertad. Introducción a Kierkegaard, Ciafic Ediciones, Buenos Aires 2006, 270 pp., ISBN 950-9010-45-6 y La posibilidad necesaria de la libertad. Un análisis del pensamiento de Søren Kierkegaard, Cuadernos de Anuario Filosófico, Serie Universitaria 177, Pamplona 2005, 116 pp., ISSN 1137-2176.

Líneas de investigación:

Sus investigaciones se centran en el pensamiento de S. Kierkegaard, con especial referencia al idealismo alemán y a la filosofía francesa contemporánea.

Dirección postal:

Rivadavia 1082, Luján - CP. 6700, Buenos Aires, Argentina

Dirección electrónica: mjbinetti@yahoo.com.ar 
